\author{
Available online at https://www.rjtl.org \\ Volume: 1, Issue: 2, 53-55, 2020 \\ ISSN: $2708-3632$ \\ DOI: https://doi.org/10.46590/rjtl.2020.010204
}

\title{
Removal of Nicotine by Sorption Technique using Titanium Dioxide and Mentha Peperita with Hydrophobic Treatment
}

\author{
R. Parthipan ${ }^{1}$, K. Rajkaran ${ }^{1}$, P.Rekha ${ }^{1}$, M.Soniyaa ${ }^{1 *}$ and M. Jesima ${ }^{2}$ \\ ${ }^{1}$ Final Year Student, ${ }^{2}$ Assistant Professor, \\ Department of Fashion Technology, Sri Krishna Engineering College, Chennai-18, Tamil Nadu, India.
}

Paper History

Received : July 2020

Accepted : August 2020

Published : August 2020

Corresponding Author

M.Soniyaa

soniyaasweety98@gmail.com

\begin{abstract}
Textile is an indispensable part of human life. Textile finishing not only enhances the feel and drape of fabrics but can also provide extraordinary hygienic properties like making it anti-microbial. The titanium dioxide doped with Nanoparticles increases their susceptibility to sorption of nicotine and accelerates its decomposition. Extraction of menthe piperita is applied to the fabric with titanium dioxide. Hydrophobic and vinegar (used as modrant) by boiling with dip and dry method on $100 \%$ cotton plain-woven fabric water-based super hydrophobic coating is an aqua emulsion and containing flammable solvent regarding water, soil and oil repellency after drying. The Sample with higher antimicrobial activity is found by the results and a Government is made for women. This Study makes a way for the usage of eco-friendly and safe product which is produced using mentha on cotton fabric.
\end{abstract}

Keywords: Anti-Bacterial activity, Dip and Dry, Mentha Piperita, Titanium Dioxide.

Citation: R. Parthipan, K. Rajkaran, P.Rekha, M.Soniyaa and M.Jesima, Removal of Nicotine by sorption technique using Titanium dioxide and Mentha Peperita with Hydrophobic Treatment, Research Journal of Textile and Leather, 1(2), 53-55, 2020.

\section{INTRODUCTION}

Handloom Textile materials, because of their specific characters and affect the content of volatile pollutants in the environment, including constituents of tobacco smoke The susceptibility of sorption was tested and it was found cotton fabric has the susceptibility of absorption nicotine, which is a highly addictive component [1].

The decomposition by Titanium dioxide doped chemical treatment. A comparison of the decomposition of rate constants for the modified and unmodified fiber shows that the decomposition process runs from 1.6 to 2.9 times faster for the modified fibers depending on the nature of modification[2].

In our study, the photocatalytic effectiveness of the fibers was evaluated based on sorption and the nicotine decomposition rate under the different condition and also studied the effect of the photocatalytic modification on the Physicochemical properties of fibers[3].

Cotton fiber contains physical and chemical properties that induce good comfort, thermal resistant, high durability, absorbency, ease of finishing and dyeing. It is one of the most preferable fibre because it has good drape and texture [4].
Natural treatment using herbal plant Mentha Piperita works as antimicrobial in textile finishing. Herbal Medicinal Plant has been the basis of treatment and cure for various disease and physiological condition in traditional method practised in India. It is precisely the natural biomedical effect, which forms the basics for sanitized and mentactive odour in textile finishing [5].

Hydrophobic solution and vinegar act as a mordant which helps in odour free and stain free and it is soil, oil, water repellent.[6]

Inherent properties of textile fibres provide an opportunity for the growth of microorganisms. Herbs are copiously available in nature, non-toxic and are economical. Extracts from a plant which exhibit antibacterial properties.

Due to their eco-friendly nature, it has a higher\% of acceptance in the market. These antibacterial extracts can be used as the textile finishing agents in the solvent [7].

\section{MATERIAL AND METHODS}

Materials Cotton is a natural vegetable fiber which provides good warmth, feel and texture to the wearers comfortable. Cotton fiber can attain good absorption and moisture content. Selecting100\%. Pure cotton for 
this study to obtain the accurate product. Cotton fabric may contain natural impurities, and they are removed by scouring Process during manufacturing

\subsection{Collection of Plant Materials}

The plant Mentha peperita was obtained from the natural environment. The plant is placed under the sunlight. Those plants are placed under room temperature. The dried plants of Menthapeperita have Antimicrobial properties which aid in natural treatment.

\subsection{Collection of Chemical Material}

The Titanium dioxide can decompose the nicotine by sorption technique. Titania powder is dry roasted and set for further treatment with mentha.

\subsection{Method of Extraction}

The herbs are dried under sunlight for about 2 to 3days. Then the titania powder is boiled for 30 minutes, After that mentha extract are allowed to is mix well in the boiled water, now the solutions were prepared. The mentha and titania fine powder is boiled well for one hour under a suitable temperature for deep penetration of the fine powder in the water.

\subsection{Method of Finishing}

Sample cloth $25 \mathrm{~cm} \times 25 \mathrm{~cm}$ cotton woven fabric was treated with $500 \mathrm{ml}$ of optimized treated solution. The solution was stirred well for better fixation for every 10 minutes. The fabric was dipped into the solution for about 6-7 hours. Then the fabric sample is taken out, squeezed and dried for 12 hours (shadow dry) without washing. After drying the fabrics are treated with the hydrophobic solution for stain, oil, water repellent.

\subsection{Evaluation of Test Report}

As per the ASTM test method, The antimicrobial activity of the control sample was evaluated by the American Association of Textiles Chemist and Colorists 100 Test method. The sample was neutralized in phosphate buffer solution at $24+/-1^{\circ} \mathrm{C}$ for 1 hour. The samples were placed on the surface of the medium and the dishes were kept for incubation at $40^{\circ} \mathrm{C}$ for 24 hours. At the end of the incubation, the zone of incubation was formed around the fabric was ensured in centimetre and recorded.

The treated sample was analyzed for their wash durability by subjecting the samples to washing and testing their antimicrobial efficiency by Disc diffusion method. The ISO 105 C06 : 2010 test method was followed to analyze the colour fastness to washing. The laundro meter was used for this purpose. The abrasion resistance of the sample was tested in Martindale abrasion tester. The ISO 12945-2-2010 test method was followed.

\section{RESULT AND DISCUSSION}

\subsection{Antibacterial Activity}

Table 1. display the antibacterial activity of control and treated sample against staphylococcus Aureus and Escherichia coli were evaluated by disc diffusion method.

Table 1. Antibacterial Test

\begin{tabular}{cc}
\hline Test Microorganism & $\begin{array}{c}\text { Reduction of } \\
\text { Bacteria (\%) }\end{array}$ \\
\hline Escherichia coliform & $99.9 \%$ \\
Staphylococcus aureus & $99.9 \%$ \\
\hline
\end{tabular}

\subsection{Colour Fastness to Washing}

Table 2 displays the antibacterial activity was evaluated after washing at $40^{\circ} \mathrm{C}$ for 30 minutes. The herbal finished fabric showed good antibacterial activity against both staphylococcus aureus and Escherichiacoli.

Table 2. Colour Fastness to Washing

\begin{tabular}{cc}
\hline Particulars & Report Value \\
\cline { 1 - 1 } Colour Change & 4 \\
\cline { 1 - 1 } Base & 4 \\
\cline { 1 - 1 } Staining & \\
\cline { 1 - 1 } Acetate & $4-5$ \\
Cotton & 3 \\
Nylon & 3 \\
Polyester & 3 \\
Acrylic & $4-5$ \\
Wool & $4-5$ \\
\hline
\end{tabular}

\subsection{Abrasion Resistance}

Table 3 display the abrasion resistance of the sample was evaluated by Martindale abrasion tester. The sample showed a good report value.

Table 3. Abrasion Resistance

\begin{tabular}{cc}
\hline Particulars & Value \\
Length (Wales) & Grade-4 \\
Width(Course) & Grade-4 \\
\hline
\end{tabular}

\section{CONCLUSIONS}

The results proved that the selected herb and chemical such as Mentha piperita and titanium dioxide were suitable for antibacterial finishing on woven cotton fabric. The hydrophobic solution used is stain resistant. The herbal finished sample showed good antibacterial activity against Staphylococcus aureus and Escherichia coliform. Hence it is considered as Eco-friendly method of finishing. 


\section{REFERENCES}

[1]. Cieślak M, Schmidt H, Świercz R, Wąsowicz W (2014) Fibers susceptibility to contamination by environmental tobacco smoke markers. Text Res J 84:840-853

[2]. Hu J, DesMeules M (2007) Environmental tobacco smoke and cancer. In: Jeorgensen NA (ed) Passive smoking and health research. Nova Science Publishers, Inc., New York, pp 215-243

[3]. Cieślak M (2006) New approach to environmental tobacco smoke exposure and its relation to reemission processes. Int $\mathrm{J}$ Occup Med Environ 19:92-98

[4]. American Association of Textile Chemists and Colorists: Water Repellency: Spray Test. AATCC Test Method 22-2005 (2005)

[5]. Bakli, C., Chakraborty, S.: Slippery to the sticky transition of hydrophobic nanochannels. Nano Lett. 15, 7497-7502 (2015).

[6]. López-Aguilar, Saúl et al. "Soil Odor as An Extra-Official Criterion for Qualifying Remediation Projects of Crude OilContaminated Soil." International journal of environmental research and public health vol. 17,9 3213. 5 May. 2020, doi:10.3390/ijerph17093213

[7]. El-Shafei, M.K. El-Bisi, S. Zaghloul * and R. Refai, Herbal Textile Finishes - Natural Antibacterial Finishes for Cotton Fabric, Egypt. J. Chem. 60, No. 2, pp. 161- 180 (2017), DOI: 10.21608/ejchem.2017.541.1001 